International Journal of Development, Vol.8, No.(1) (2019): 113-121

ISSN: 2314-5536

e-ISSN: 2314-5544 (Online)

www. ijd.byethost13.com

e-mail: fas_ijd@yahoo.om

\title{
Biophysical study to enhancement of apoptosis in colon cancer cell line using silver nanoparticles driven by extremely low frequency magnetic field and electroporation
}

\author{
Ebtesam Abd Elghany Mohamad \\ Biophysics Department, Faculty of Science, Cairo University
}

\begin{abstract}
Extremely low frequency magnetic field (EMF) with an intensity of $0.01 \mathrm{mT}$ is used to intensify the effect of the Silver nanoparticles (SNPs) as an anticancer agent. EMF stimulates the movement and vibration of SNPs that may enhance the apoptotic process in colon cancer ( $\mathrm{CaCo} 2$ cell lines). Electroporation (EP) is used to improve targeting of cancer cells, where pulsed electric field $(200 \mathrm{~V})$ creates hydrophilic gaps in cell membrane leading to elevated SNPs transport into colon cancer cells. $\mathrm{CaCo} 2$ cell lines are divided into 6 groups according to treatment type. Results show a clear accumulation during the G2/M phase of arrested cells accompanied by an extremely significant apoptotic percentage $7.59 \%$ for cell lines treated with silver nanoparticles, electroporated and then exposed to electromagnetic field $(0.01 \mathrm{mT})$ for $1 \mathrm{hr}(\mathrm{EP}+\mathrm{EMF}+\mathrm{SNPs}+\mathrm{Cells})$. A significant apoptotic percentage $4.12 \%$ is also reported in the group: $\mathrm{EP}+\mathrm{SNPs}+\mathrm{Cells}$. The lethal effect of the combination of EP, $\mathrm{EMF}$ and SNPs on $\mathrm{CaCo} 2$ cell lines is further reinforced by comparing the regulation of apoptotic genes (P53, Caspase-3, BCL-2) with its corresponding values in the control cells. The combination of EP, EMF and SNPs is probably a promising method for colon cancer treatment.
\end{abstract}

Key words: Colon cancer; silver nanoparticles; low frequency magnetic field; electroporation; $\mathrm{CaCo} 2$ cell lines.

\section{INTRODUCTION}

Cancer is one of the major diseases that affects human kind worldwide. It is known to be a complex, multifunctional disease due to its ability to spread in normal cells due to different genetic or environmental factors ${ }^{[1,2,3]}$. Colon cancer is known to be an aggressive kind of cancer as it occurs when the body lacks the ability to absorb water as well as salts from solid waste, hence leading to non-controllable overgrowth of cells in the large intestine. Known symptoms of colon cancer include constipation, diarrhea, Irritable Bowel Syndrome (IBS), and rectal diseases. Common, cancer therapies include chemotherapy, surgery, immunotherapy, hormone therapy, or radiation therapy, however, these methods lack directed delivery to cancer cells ${ }^{[4]}$.

On the other hand, Silver nanoparticles have shown its ability to overcome the effects that accompany cancer therapies as it leads to direct drug therapy with few side effects ${ }^{[5]}$. In addition, silver has many properties that have been used for treatment of various diseases, for instance, it serves as an antibacterial or antimicrobial agent because of the well-developed surface of silver nanoparticles which provides the maximum contact with the environment ${ }^{[6]}$. Studies in the past years have shown that silver nanoparticles can be successfully used as an anticancer agent due to its anti-proliferation and apoptosis induction properties ${ }^{[7]}$.

The present work investigates the incorporation of additional factor that may help in the apoptotic induction process in cancer treatment (electroporation, EP) and is reported to improve the efficacy of silver nanoparticles and it is use in specific cell targeting ${ }^{[\mathbf{8}]}$. Using EP, cells are exposed to pulsed electric field resulting in abnormal increase in the permeability of the outer membrane. Hence EP is used in many applications due its ability to 
cause temporary hydrophilic gaps in the cell, thus reducing transmembrane resistance and allowing the passage of drugs into the viable cells ${ }^{[9,10]}$. Another influencer in this study is the Low Frequency Magnetic Field (ELF-MF) or (EMF) as it has the ability to cause changes in the metabolism of cells when treated with precise frequencies and amplitudes. EMF is known for its ability to overcome cell proliferation caused by cancer cells as well as enhancing the apoptosis process ${ }^{[11,12]}$. Other existing works exposed cancer cells to nanoparticles with EMF, here the formed membrane pores by EP target specific cells that decrease the lethal side effect to normal cells.

Therefore, the aim of this study is to evaluate the use of electromagnetic field in conjunction with electroporation and silver nanoparticles in the treatment of colon cancer cells and to determine the way this method affects internal structures, genes and rate of apoptosis.

$\underline{\text { Materials }}$

\section{MATERIALS AND METHODS}

Silver nitrate and tri-sodium citrate were purchased from Sigma Aldrich, USA. Cell line $\mathrm{CaCo} 2$ (Colon Cancer Cell line) was provided by the Tissue Culture Department, Vaccines \& Sera (VACSERA), Egypt and Fetal bovine serum (FBS) was purchased from Invitrogen Corp., Carlsbad, CA. Phosphate-buffer saline (PBS) was purchased from ADWIA-Egypt. Penicillin-streptomycin, Trypsin, EDTA, and Hank's buffer were purchased from Gibco, USA. There was no further purification of the reagents.

\section{Methods}

\section{Silver nanoparticles preparation}

Silver nanoparticles (SNPs) were prepared by reduction procedure in low concentration, to minimize the toxic effect of SNPs as much as possible. Therefore, $0.0024 \mathrm{~g}$ of sodium nitrate/ $100 \mathrm{ml}$ water was mixed drop wise with $0.029 \mathrm{~g} / 50 \mathrm{ml}$ of Tri-sodium citrate at $100{ }^{\circ} \mathrm{C}$ using a magnetic stirrer. The color change was observed as yellow color that would start to appear once silver nanoparticles were formed.

\section{Identification and characterization of SNPs}

Spectrophotometer (SHIMADZU QP2010, Japan) was used to test the absorbance of silver nanoparticles. It revealed an absorption peak at $450 \mathrm{~nm}$, hence the concentration of the silver nanoparticles used was $7.45 \times 10^{-9} \mathrm{~m}$ mol / L. In addition, Characterization of silver nanoparticle shape was carried out using Transmission Electron Microscope (TEM) and later, samples were stored in sterilized cuvette for further used.

\section{Cell culture}

Colon cancer cell lines $(\mathrm{CaCo} 2)$ were provided by tissue from VACSERA, Egypt. $\mathrm{CaCo} 2$ cells were maintained as monolayer culture in RPMI-1640 medium supplemented with $10 \%$ Fetal Bovine Serum (FBS) and $1 \%$ penicillin-streptomycin at $37{ }^{\circ} \mathrm{C}$ in a $\left(5 \% \mathrm{CO}_{2}\right)$ humid atmosphere. When the cells reached at least $80 \%$ confluence, they were washed twice with Phosphate-Buffer Saline (PBS) and were detached with $0.25 \%$ trypsin/EDTA in Hank's buffer. An equal volume of medium with FBS for trypsin inactivation was added and the tumor cells were collected and counted.

\section{Electroporation (EP) and Electromagnetic field (EMF) treatments}

The suspended $\mathrm{CaCo} 2$ cells $\left(2 \times 10^{4} / 2.5 \mathrm{ml}\right)$ were seeded in cell culture petri-dishes ( $8 \mathrm{~cm}$ in diameter) and incubated at $37{ }^{\circ} \mathrm{C}(5 \% \mathrm{CO} 2)$. Cells were divided into 6 test tubes 
Biophysical study to enhancement of apoptosis in colon cancer cell line using silver nanoparticles driven by extremely low frequency magnetic field and electroporation

according to the treatment type: Control $\mathrm{CaCo} 2$ cells, EP+Cells, EMF+Cells, $\mathrm{EP}+\mathrm{EMF}+\mathrm{Cells}, \mathrm{EP}+\mathrm{SNP}+\mathrm{Cells}$ and $\mathrm{EP}+\mathrm{EMF}+\mathrm{SNPs}+\mathrm{Cells}$, (Table 1). Using EP, cells were exposed to 10 pulses of $200 \mathrm{~V}$ each at equal intervals of time by the electroporator (BIORAD, USA). The electromagnetic field intensity used was 0.01 Tesla. An amount of 0.5 $\mu \mathrm{g} / \mathrm{ml}$ SNPs was mixed thoroughly with cells treated with SNPs then tested for cell cycle, apoptosis and molecular analysis including P53, BCL2, Casp-3, and Survuvin investigations.

Table 1. Details of the 6 different investigated groups.

\begin{tabular}{lll}
\hline Test Tubes & $\mathrm{mV}$ & $\mathrm{mT}$ \\
\hline Control CaCo2 & - & - \\
\hline EP+Cells & $200 \mathrm{~V}$ & - \\
\hline EMF+Cells & & 0.01 \\
\hline EP+ EMF+Cells & $200 \mathrm{~V}$ & 0.01 \\
\hline EP+SNPs+Cells & $200 \mathrm{~V}$ & - \\
\hline EP+ EMF + SNPs+ Cells & $200 \mathrm{~V}$ & 0.01 \\
\hline
\end{tabular}

\section{Cell cycle analysis by flow cytometry}

Cell cycle phase distribution was evaluated using a method described by Poolman and Brooks [9] with minor modifications. Cells were seeded in flask $(1 \times 106$ cells/ flask $)$, and treated with the IC50 of free sinapic acid and niosome encapsulating sinapic acid and incubated for $24 \mathrm{~h}$. The cells were then harvested, centrifuged, and fixed in ice-cold $70 \%$ ethanol. The fixed cells were again centrifuged and resuspended in $100 \mu \mathrm{L}$ of PBS. The cells were incubated with RNase A and stained with a propidium iodide solution. The labeled cells were analyzed using a FACSCan flow cytometer (Becton Dickinson).

\section{Apoptosis analysis}

Induction of apoptosis in control, free sinapic acid and niosome encapsulating sinapic acid was assayed using flow cytometry according to the manufacturer's instructions flow cytometer laboratory protocol.

\section{Statistical analysis}

Data are analysed using the Duncan's multiple range test by SPSS software (version 17; SPSS, Chicago, IL). The differences are considered significant at $\mathrm{P}<0.001$

\section{RESULTS \\ 1. Identification and characterization of SNPs \\ UV-Visible absorption spectrum}

Silver nanoparticles previously reported exceptional optical, electrical and thermal properties, where spherical and/or circular silver nano-particles with diameter smaller than $50 \mathrm{~nm}$ in size showed an absorption peak at 470-490 $\mathrm{nm}$. The increase in the size of nanoparticles and their aggregation would lead to sensible broadening of the absorption peak and its shift towards higher wavelengths ${ }^{[13]}$. In the present work, the prepared SNPs reveal a peak at a wavelength of $455 \mathrm{~nm}$ (Fig. 1), reflecting that their size is probably smaller than 50 nm. 
Ebtesam A. Mohamad

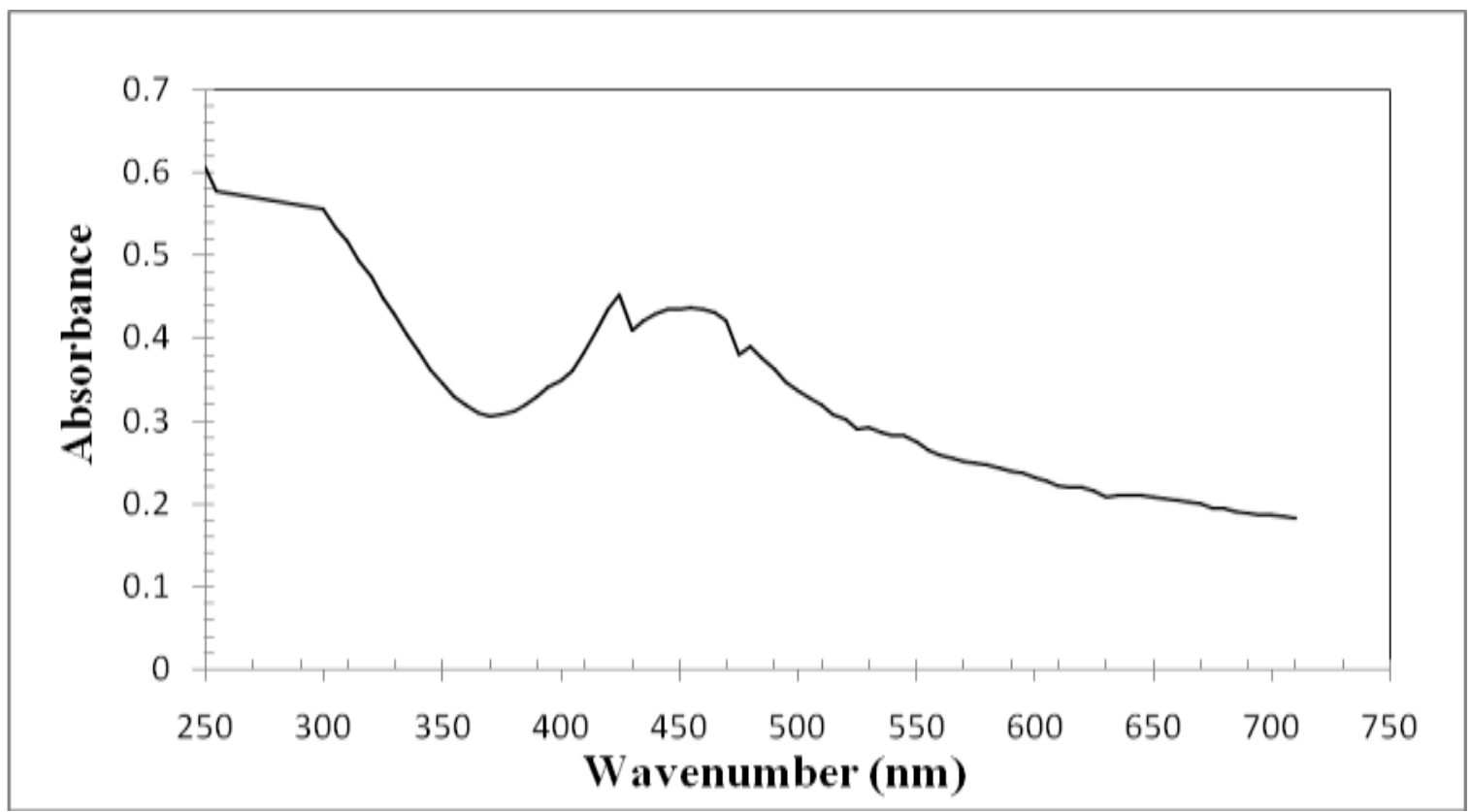

Fig. 1. UV-Visible absorption spectrum of SNPs.

\section{Transmission electron microscopy}

The examination of the ultra-structure using TEM shows that the prepared SNPs are homogenous, non-aggregated, spherical shape particles of comparable size (Fig. 2).

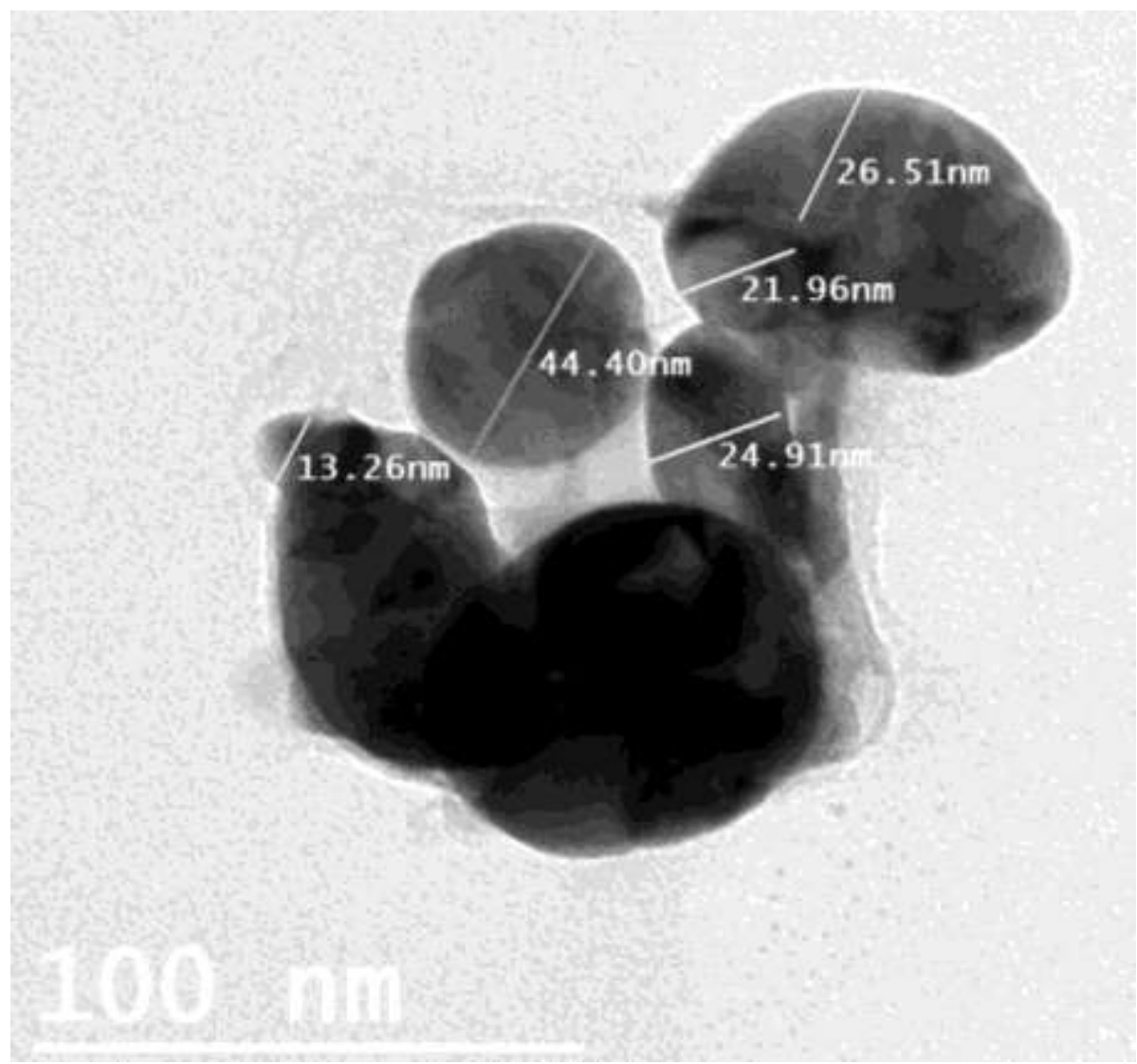

Fig. 2. TEM image of SNPs. 
Biophysical study to enhancement of apoptosis in colon cancer cell line using silver nanoparticles driven by extremely low frequency magnetic field and electroporation

\section{The treatments protocols on $\mathrm{CaCo} 2$ cell line}

Human colon cancer cell line $(\mathrm{CaCo} 2)$ treated using electroporation followed by one hour exposure to electromagnetic field $(0.01 \mathrm{mT})$ shows no effect on cell viability. The viability percentage is determined using MTT assay and shows a value ranging between 95$100 \%$. Regarding the apoptotic profile induced in EP+SNPs+Cells and $\mathrm{EP}+\mathrm{EMF}+\mathrm{SNPs}+\mathrm{Cells}$, it is noticed that there are a clear accumulation of the arrested cells during the G2/M phase (Fig. 3a). The percentage of cell arrest is dependent on the presence of SNPs, where there is a significant $(\mathrm{P}<0.05$ and $\mathrm{P}<0.001)$ arrest percentages for $\mathrm{EP}+\mathrm{SNPs}+\mathrm{Cells}$ and $\mathrm{EP}+\mathrm{EMF}+\mathrm{SNPs}+$ Cells groups, respectively (Fig. 3b). In the meantime, the cell arrest is accompanied by cell profile characterized by significant $(\mathrm{P}<0.005$ and $\mathrm{P}<0.0001$ ) apoptotic percentages for $\mathrm{EP}+\mathrm{SNPs}+\mathrm{Cells}$ and $\mathrm{EP}+\mathrm{EMF}+\mathrm{SNPs}+\mathrm{Cells}$ groups, respectively. The arrest and apoptotic profiles of the other groups show insignificant changes $(\mathrm{P}>0.05)$ compared to control.
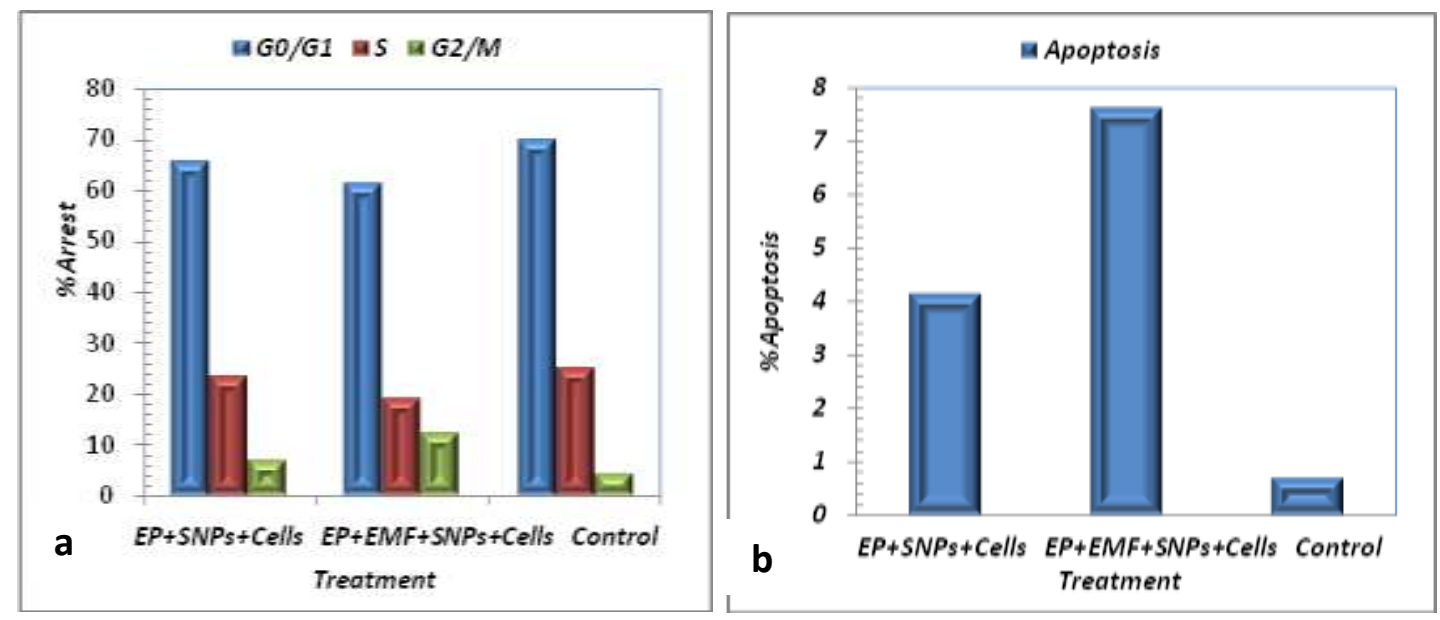

Fig. 3. (a) The variation of \% arrest for cell cycles G0/G1, S and G2/M and (b) \% apoptosis for EP+SNPs+Cells, EP+ EMF+ SNPs+Cells and control samples.

Regarding the apoptotic gene profiles induced in $\mathrm{CaCo} 2$ cells for groups $\mathrm{EP}+\mathrm{SNPs}+\mathrm{Cells}$ and $\mathrm{EP}+\mathrm{EMF}+\mathrm{SNPs}+\mathrm{Cells}$, it is noticed that there is a significantly $(\mathrm{P}<0.05)$ elevated up regulation of apoptosis P53 gene compared with control cells. A significant difference $(\mathrm{P}<0.05)$ exists in the up regulation rate for group $\mathrm{EP}+\mathrm{EMF}+\mathrm{SNP}+\mathrm{Cells}$ compared to group $\mathrm{EP}+\mathrm{SNP}+\mathrm{Cells}$. In the meantime, there is a significant $(\mathrm{P}<0.05$ and $\mathrm{P}<0.005)$ increase in up regulation of Caspase-3 gene compared to control for $\mathrm{EP}+\mathrm{SNPs}+\mathrm{Cells}$ and EP+EMF+SNPs+Cells groups, respectively (Fig. 4). For BCL-2, the $\mathrm{EP}+\mathrm{SNPs}+\mathrm{Cells}$ group is insignificantly $(\mathrm{P}>0.05)$ down regulated compared to control, while the $\mathrm{EP}+\mathrm{EMF}+\mathrm{SNPs}+\mathrm{Cells}$ group is significantly $(\mathrm{P}<0.05)$ down regulated compared to control. For survivin, both groups are significantly $(\mathrm{P}<0.05)$ down regulated compared to control. The down regulation in both groups are statistically similar. 
Ebtesam A. Mohamad

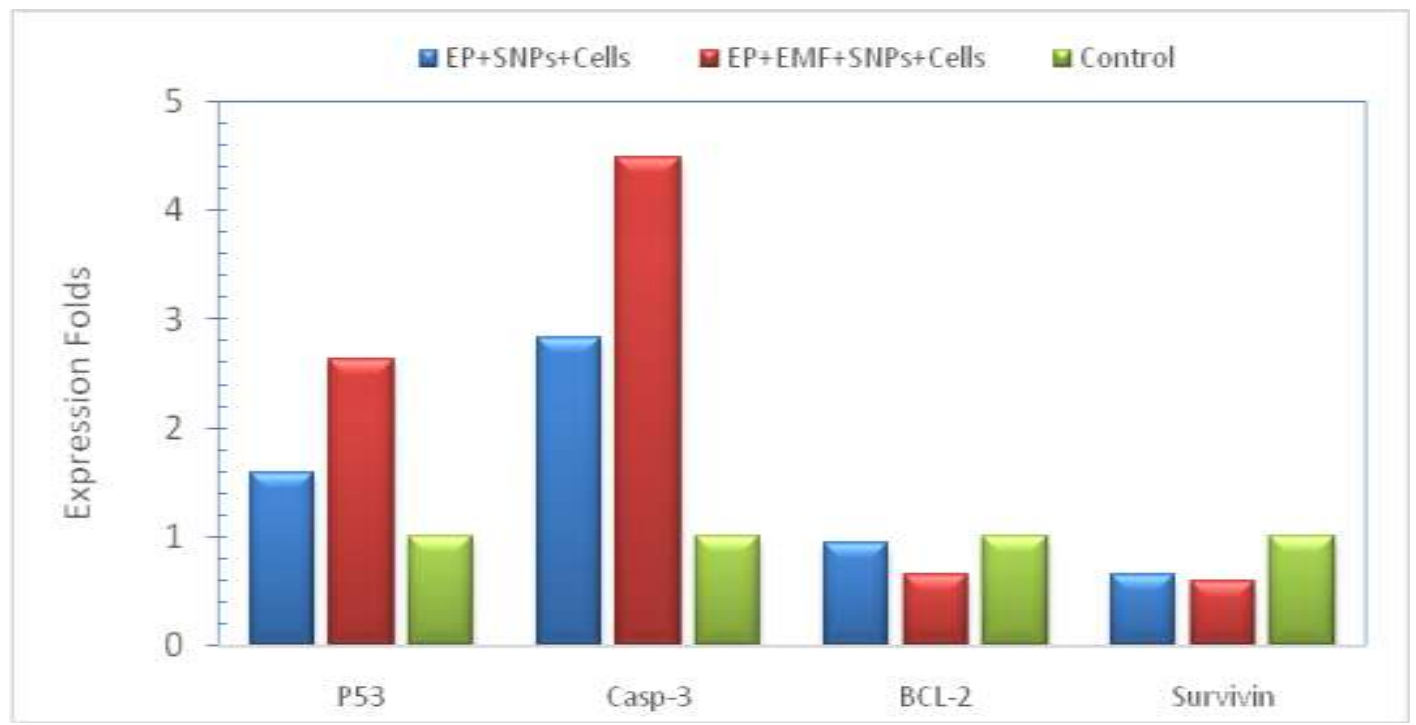

Fig.4. Apoptotic gene profile induced in EP+SNPs+Cells, EP+EMF+SNPs+Cells, and Control cells for Apoptotic genes (P53 and Casp-3) and Anti-Apoptotic genes (BCL-2 and Survivin).

\section{DISCUSSION}

The cytotoxic effect of SNPs has always attracted the attention towards possible application in cancer treatment ${ }^{[\mathbf{1 4 , 1 5}]}$. Here we emphasize the lethal effect of SNPs on CaCo2 tumor cells. SNPs alone produce reactive oxygen species (ROS) and, therefore, are capable to induce apoptosis $^{[6,16-19]}$. It has been reported also that SNPs activate signaling pathways that lead to the inhibition of cell proliferation by acting on membrane proteins ${ }^{[16,20,21]}$. It should be noted that silver nanoparticles can also enter cells through endocytosis where the high surface area of SNPs increases the interaction with fluid components compared with bulk particles producing mitochondrial dysfunction, destruction of proteins and nucleic acids, formation of reactive free radicals. All of these effects strongly enhance the inhibition of cell proliferation $^{[6,16-19,22]}$.

This work also examines a novel approach involving the introduction of electroporation (EP) in order to facilitate the entrance of SNPs into tumor cells, in addition to the initiation of localized tumor cell damage ${ }^{[23]}$. Moreover, in order to maximize the potential effects of SNPs, EMF is applied in conjunction with EP. The exposure of cells to EMF is expected to enhance the formation of membrane pores as a result of interaction between the externally applied EMF and the magnetic properties of cell membranes ${ }^{[24]}$.

ROS are generally considered one important effect of the application of various anticancer agents on cell cycle phases ${ }^{25,26]}$. It is reported that SNPs stimulate an elevation in the intracellular $\operatorname{ROS}^{[6,16-19]}$. Therefore SNPs induce apoptosis or cell cycle arrest by increased production of ROS. In the present work, EP+SNPs+Cells and $\mathrm{EP}+\mathrm{EMF}+\mathrm{SNPs}+\mathrm{Cells}$ induce increased accumulation of cells in the G2/M phase in addition to increased cell apoptosis (Fig. 3) probably due to the increase in DNA damage caused by the increased production of ROS which, in turn, cause increased inhibition of proliferation in the $\mathrm{CaCo} 2$ cell lines. $\mathrm{CaCo} 2$ cells were most sensitive to $\mathrm{EP}+\mathrm{EMF}+\mathrm{SNP}+\mathrm{Cells}$ protocol.

Our findings demonstrate that the examined SNPs treatments may serve as protective agents against colon cancer, where it is observed that the apoptosis ratio increased to $4.12 \%$ and $7.59 \%$ in $\mathrm{EP}+\mathrm{SNPs}+\mathrm{Cells}$ and $\mathrm{EP}+\mathrm{EMF}+\mathrm{SNPs}+\mathrm{Cells}$ treatments, respectively, compared to control cells $0.68 \%$. 
Apoptosis controlled cell death by a series of morphological events and is carried out by an active cellular process. One of the principal signaling transduction pathways involved in the process of apoptosis is the mitochondrial pathway ${ }^{[27]}$. In the present study it is initiated by the up regulation of $\mathrm{p} 53$ by 1.59 and 2.63 folds, followed by suppression of Bcl-2 by 0.95 and 0.65 folds in $\mathrm{EP}+\mathrm{SNPs}+\mathrm{Cells}$ and $\mathrm{EP}+\mathrm{EMF}+\mathrm{SNPs}+\mathrm{Cells}$ treatments, respectively, compared to control cells. These results suggest that SNPs stimulates the reduction in mitochondrial transmembrane potential and the release of mitochondrial cytochrome c, finally activating the mitochondrial-mediated apoptosis pathway ${ }^{[15,28]}$. The activation of caspase- 3 by 2.83 and 4.48 folds in $\mathrm{EP}+\mathrm{SNPs}+\mathrm{Cells}$ and $\mathrm{EP}+\mathrm{EMF}+\mathrm{SNP}+\mathrm{Cells}$ treatments, respectively is also reported. Caspases, a family of cysteine proteases, play essential role in apoptosis, necrosis and inflammation. The activation of caspase- 3 induces apoptosis through the mitochondrial pathway ${ }^{[29]}$. In the present study, it is shown that SNPs enhance caspase-3 activity, indicating that the mitochondrial death pathway is involved in the process of apoptosis induced by SNPs' treatments.

Survivin is suppressed by 0.65 and 0.60 folds in EP+SNPs+Cells and $\mathrm{EP}+\mathrm{EMF}+\mathrm{SNPs}+\mathrm{Cells}$ treatments, respectively. Survivin serves, in participation with other proteins, in the regulation of apoptosis, cell motility, and cell division ${ }^{[30]}$. The examined SNPs' treatments are shown to be able to suppress survivin function and induce cancer cell death. These treatment strategies could result in potential enhancement of the effectiveness of many drugs.

Treatment including EMF (EP+EMF+SNPs+Cells) with an intensity of $0.01 \mathrm{~T}$ is shown to produce increased damage to tumor cells. This is probably due to the ability of EMF in stimulating the movement and vibration of the SNPs that may enhance the apoptotic process. Despite electroporation-based treatment (EP+SNPs+Cells) produces enhanced cell damage due to the generation of temporary pores facilitating the entrance of SNPs across cell membrane, yet a combined treatment including both EP and EMF (EP+EMF+SNPs+Cells) clearly induces larger cell damage in $\mathrm{CaCo} 2$ cells due to the combined effect of EP and EMF.

There is no significant effect on tumor cells upon treatment by EP only under pulsed voltages of $200 \mathrm{~V}$ and $260 \mathrm{~V}$ (data not shown). A combination of SNPs and EP show a moderate enhancement in cell damage parameters compared to control.

\section{Conclusion}

In conclusion, we offer an in vitro study that examines the possibility to enhance specific $\mathrm{CaCo} 2$ cell damage through the application of SNPs combined to Ep+EMF. A highly evident intracellular damage is produced since EP induce membrane pores through the exposed cells. Therefore, this study strongly recommends a future in vivo application of such protocol for the treatment of $\mathrm{CaCo} 2$ cells.

\section{REFERENCES}

1- Stare, S.M. and Jozefowicz, J.J. (2008). The Effects of environmental factors on cancer prevalence rates and specific cancer mortality rates in a sample of oecd developed countries. Int. J. Appl. Econ. 5(September):92-115

2- Kabel, A.M. (2017). Tumor markers of breast cancer: New prospectives. J. Oncol. Sci. 3(1):5-11. doi:10.1016/j.jons.2017.01.001.

3- Reshetnikova, G.; Sidorenko, V.S.; Whyard, T. et al. (2016). Genotoxic and cytotoxic effects of the environmental pollutant 3-nitrobenzanthrone on bladder cancer cells. Exp. Cell. Res.,349(1):101-108. doi:10.1016/j.yexcr.2016.10.003. 
4- Zhang, C-L.; Huang, T.; Wu, B-L.; He, W-X. and Liu, D. (2017). Stem cells in cancer therapy: opportunities and challenges. Oncotarget, 8(43):75756-75766. doi:10.18632/oncotarget.20798.

5- Singh, J.; Singh, T. and Rawat, M. (2017). Green Synthesis of silver nanoparticles via various plant extracts for anti-cancer applications. Glob. J. Nanomed., 2(3):2-5. https://juniperpublishers.com/gjn/pdf/GJN.MS.ID.555590.pdf.

6- Maliszewska, I. and Puzio, M. (2009), Extracellular biosynthesis and antimicrobial activity of silver nanoparticles. ACTA PHYSICA POLONICA A 116:160-162.

7- Yuan, Y-G.; Peng, Q-L. and Gurunathan, S. (2017). Silver nanoparticles enhance the apoptotic potential of gemcitabine in human ovarian cancer cells: combination therapy for effective cancer treatment. Int. J. Nanomedicine, 12: 6487-6502. doi:10.2147/IJN.S135482.

8- Bian, S.; Zhou, Y.; Hu-Y.; Cheng, J.; Chen, X., Xu-Y. and Liu-P (2017). High-throughput in situ cell electroporation microsystem for parallel delivery of single guide RNAs into mammalian cells. Scientific Reports, 7:1-13

9- Sandri, M.; Bortoloso, E.; Nori, A. and Volpe, P. (2003). Electrotransfer in differentiated myotubes: A novel, efficient procedure for functional gene transfer. Exper. Cell Res., 286 (1):87-95. https://doi.org/10.1016/S0014-4827(03)00097-1

10- Sweeney, D.C.; Reberšek, M.; Dermol, J.; Rems, L.; Miklavčič, D. and Davalos, R.V. (2016). Quantification of cell membrane permeability induced by monopolar and highfrequency bipolar bursts of electrical pulses. Biochim. Biophys. Acta - Biomembr., 1858 (11):2689-2698. doi:10.1016/j.bbamem.2016.06.024.

11- Santini, M.T.; Ferrante, A.; Rainaldi, G.; Indovina, P. and Indovina, P.L. (2009). Extremely low frequency (ELF) magnetic fields and apoptosis: a review. Int. J. Radiation Biol., 81(1):1-11.

12- Storch, K.; Dickreuter, E.; Artati, A.; Adamski, J. and Cordes, N. (2016). BEMER electromagnetic field therapy reduces cancer cell radioresistance by enhanced ROS formation and induced DNA Damage. PLoS One 11(12):1-19. doi:10.1371/journal.pone.0167931.

13- Paramelle, D.; Sadovoy, A.; Gorelik, S.; Free, P.; Hobley, J. and Fernig, D.G. (2014). A rapid method to estimate the concentration of citrate capped silver nanoparticles from UV-visible light spectra. Analyst 139:4855-4861. doi:10.1039/C4AN00978A.

14- Asha, R.P.V.; Low, Kah.; Mun, G.; Hande, M.P. and Valiyaveettil, S. (2009). Cytotoxicity and genotoxicity of silver nanoparticles in human cells. ACS Nano. , 24: 279-290.

15- Sanpui, P.; Chattopadhyay, A. and Ghosh, S.S. (2011). Induction of apoptosis in cancer cells at low silver nanoparticle concentrations using chitosan nanocarrier. ACS Appl Mater Interfaces, 3: 218-228.

16- Roh, J-Y.; Eom, H-J. and Choi, J. (2012). Involvement of Caenorhabditis elegans MAPK signaling pathways in oxidative stress response induced by silver nanoparticles exposure. Toxicol. Res., 28:19-24.

17- Carlson, C.; Hussain, S.M.; Schrand, .A.M., et al (2008). Unique cellular interaction of silver nanoparticles: size-dependent generation of reactive oxygen species. J. Phys. Chem. B 112:13608-13619.

18- Haase, A.; Rott, S.; Mantion, A., et al (2012). Effects of silver nanoparticles on primary mixed neural cell cultures: uptake, oxidative stress and acute calcium responses. Toxicol. Sci., 126:457-468.

19- He, W.; Zhou, Y-T.; Wamer, W.G., et al. (2012). Mechanisms of the pH dependent generation of hydroxyl radicals and oxygen induced by Ag nanoparticles. Biomaterials $33: 7457-7465$. 
20- Braydich-Stolle, L.; Lucas, B.; Schrand, A.M., et al. (2010). Silver nanoparticles disrupt GDNF/Fyn kinase signaling in spermatogonial stem cells. Toxicol. Sci., 116:577-589.

21- Gopinath, P.; Gogoi, S.K.; Sanpuic, P., et al. (2010). Signaling gene cascade in silver nanoparticle induced apoptosis. Colloids Surf., B 77:240-245.

22- Akter, M.; Sikder, M.T.; Rahman, M.M., et al. (2018). A systematic review on silver nanoparticles-induced cytotoxicity: Physicochemical properties and perspectives. J. Adv. Res., 9:1-16. doi:10.1016/j.jare.2017.10.008.

23- Trainito, C. (2015). Study of cell membrane permeabilization induced by pulsed electric field - electrical modeling and characterization on biochip. Thèse de l'université ParisSaclay.

24- Romanenko, S.; Begley, R.; Harvey, A.R.; Hool, L. and Wallace, V.P. (2017). The interaction between electromagnetic fields at megahertz, gigahertz and terahertz frequencies with cells, tissues and organisms: Risks and potential. J. R. Soc. Interface, 14(137). doi:10.1098/rsif.2017.0585.

25- Sauer, H.; Wartenberg, M. and Hescheler, J. (2001). Reactive oxygen species as intracellular messengers during cell growth and differentiation. Cell Physiol. Biochem., 11: 173-186.

26- Fleury, C.; Mignotte, B. and Vayssie` re J.L. (2002).Mitochondrial reactive oxygen species in cell death signaling. Biochimie, 84: 131-141.

27- Kerr, J.F.; Wyllie, A.H. and Currie, A.R. (1972). Apoptosis: a basic biological phenomenon with wide-ranging implications in tissue kinetics. Br. J. Cancer, 26:239257. View Article : Google Scholar : PubMed/NCBI

28- Piao, M.J.; Kang, K.A.; Lee, I.K.; Kim, H.S.; Kim, S.; Choi, J.Y., et al. (2011). Silver nanoparticles induce oxidative cell damage in human liver cells through inhibition of reduced glutathione and induction of mitochondria-involved apoptosis. Toxicol. Lett., 201:92-100.

29- Li, Z.; Jo, J.; Jia, J.; et al. (2010). NIH Public Access. 141(5):859-871. doi:10.1016/j.cell.2010.03.053.Caspase-3.

30- Mckenzie1, J. and Grossman, D. (2012). Role of the apoptotic and mitotic regulator survivin in melanoma. Anticancer Res.,32(2):397-404.

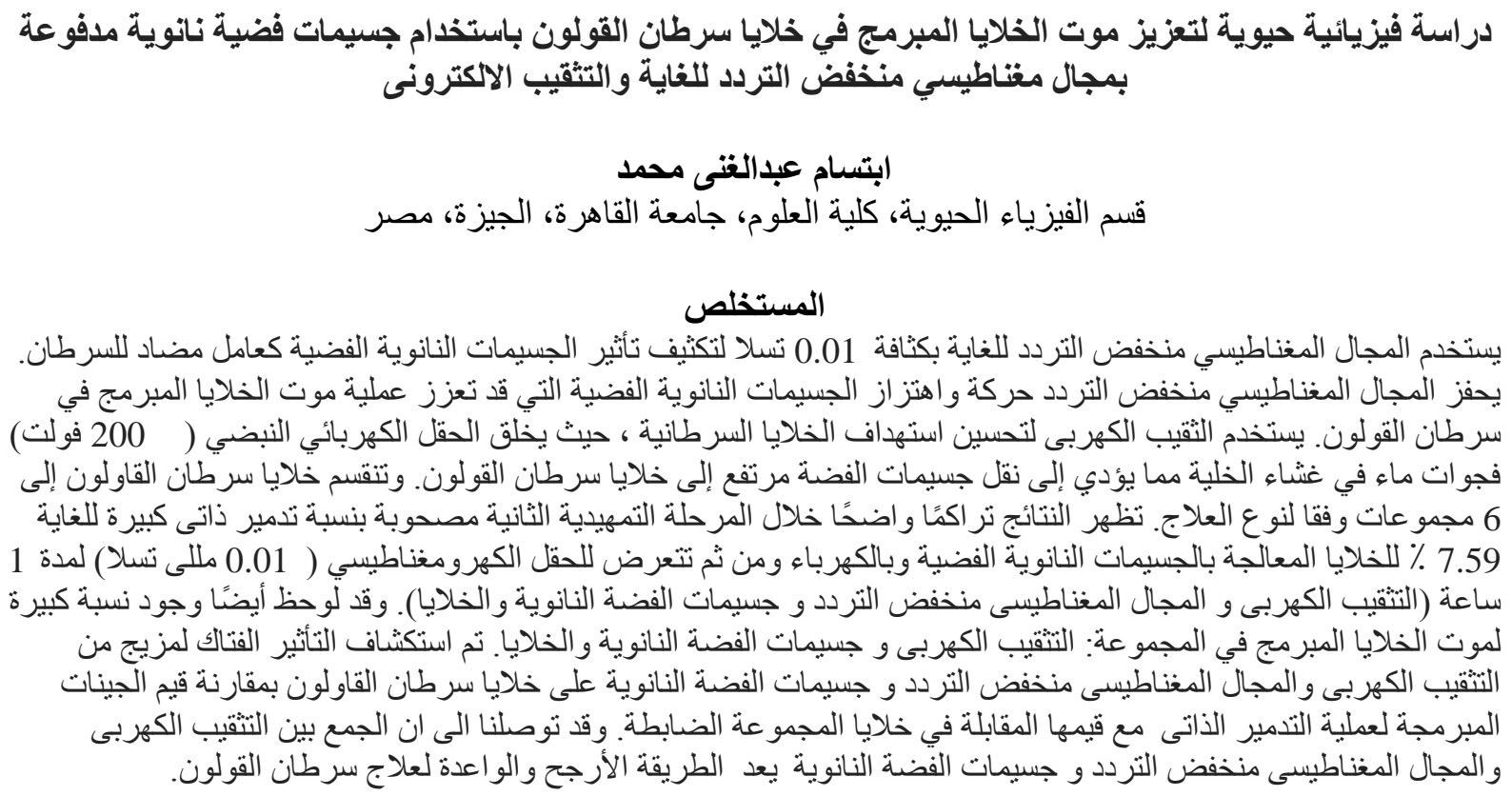

